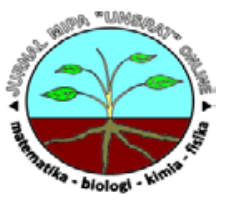

\title{
Simulasi Penjalaran Tsunami Di Beberapa Pantai Di Sulawesi Utara Sebagai Upaya Mitigasi Bencana
}

\author{
Fhandy Pandey a, Guntur Pasau a, Seni H. J. Tongkukut a* \\ aJurusan Fisika, FMIPA, Unsrat, Manado
}

KATA KUNCI

Tsunami

Simulasi tsunami

Gempabumi

\begin{abstract}
A B S T R A K
Daerah pantai utara wilayah Sulawesi Utara merupakan kawasan pesisir yang memiliki kepadatan penduduk cukup besar. Sebelah utara laut Sulawesi atau selatan Filipina berdasarkan data NOAA pernah mengalami 5 kejadian tsunami akibat gempabumi. Gempabumi yang menimbulkan tsunami ini berpotensi terulang kembali pada waktu yang akan datang. Penelitian ini bertujuan mengsimulasikan kejadian tsunami untuk mengetahui waktu tiba dan tinggi gelombang tsunami jika gempabumi tersebut kembali terjadi. Simulasi dilakukan dengan memakai software WinITDB. Jika koordinat sumber tsunami, koordinat daerah yang akan diterjang tsunami, panjang patahan, lebar patahan, deformasi dasar laut diketahui maka waktu tiba gelombang tsunami dan tinggi gelombang tsunami dapat diketahui. Dihasilkan bahwa pantai Kaidipang, Bintauna, Lolak, Poigar, Amurang, Tombariri, Manado, Siau Barat dan Tahuna termasuk dalam klasifikasi tsunami sangat berbahaya dengan tinggi $\mathrm{H} \geq$ 3 meter. Satu-satunya pantai yang termasuk dalam klasifikasi tsunami hanya bahaya yaitu pantai Beo dengan tinggi 2,3 meter.

A B S T R A C T

The northern shore of North Sulawesi is a coastal area with high population density. The north of Sulawesi Sea or the South Philippines Sea, according to NOAA's data experienced 5 tsunamis caused by earthquake. This earthquake has the potential to occur again in the future. The purpose of this study is to simulate tsunami in order to be able to predict its arrival time and the height of the tsunami wave when the earthquake happens. The simulation was performed using WinITDB software. If the coordinates of the tsunami source, impact zone, length of fracture, width of fracture, and sea floor deformation are known, the arrival time and the wave height of the tsunami can be determined. It is found that Kaidipang seashore, Bintauna, Lolak, Poigar, Amurang, Tombariri, Manado, West Siau and Tahuna are classified as dangerous tsunami zones with potential heights of $\mathrm{H}>3$. The only seashore that is classified as tsunami hazard is in the height of $1,5<\mathrm{H}<3$.
\end{abstract}

TERSEDIA ONLINE

06 Mei 2015

1. Pendahuluan

Indonesia sebagai negara yang terletak di kawasan Zona Seismik Asia Tenggara, merupakan salah satu negara dengan aktifitas seismik paling aktif bahkan teraktif di dunia (Aydan, 2008).
Kepulauan Indonesia dikelilingi oleh lempeng IndoAustralia dan lempeng Filipina yang berada di bawah lempeng Eurasia, dengan lima pulau besar dan beberapa semenanjung, telah mengalami ribuan gempabumi dan ratusan tsunami pada rentang empat ratus tahun terakhir (Aydan, 2008). 
Periode ulang tsunami, dalam beberapa kasus bisa sangat panjang, hingga ratusan tahun, seperti halnya tsunami pada 26 Desember 2004 yang melanda kawasan Samudera Hindia, merupakan perulangan tsunami yang terjadi pada tahun 1600an. Periode ulang yang sangat panjang menyebabkan manusia mudah melupakan kejadian tsunami, oleh karena itu mitigasi secara struktural maupun non struktural harus terus dilakukan dan ditingkatkan sehingga kapasitas masyarakat dalam menghadapi bencana berkembang dan diharapkan dapat meminimalkan jumlah korban dan kerugian akibat bencana tsunami (Athanasius, 2009).

Usaha mitigasi becana tsunami membutuhkan informasi tentang wilayah-wilayah yang potensial diterjang gelombang tsunami, kapan gelombang tsunami akan menghempas pantai jika gempa dan tsunami terjadi serta berapa ketinggian gelombang tsunami yang mungkin akan datang. Berdasarkan keperluan tersebut dilakukan studi simulasi penjalaran gelombang tsunami. Studi simulasi tersebut bertujuan untuk mengetahui penyebaran gelombang tsunami dari sumber tsunami ke beberapa pantai di utara wilayah Sulawesi utara, waktu tiba (arrival time) yang diperlukan gelombang tsunami dari sumber tsunami ke beberapa pantai di wilayah tersebut, dan ketinggian maximum (Hmax) tsunami sebagai bahan acuan bagi pemerintah daerah Sulawesi Utara serta masyarakat untuk pengembangan pembangunan di daerah pesisir utara wilayah Sulawesi Utara. Simulasi akan dilakukan dengan menggunakan software WinITDB.

Tsunami adalah gelombang laut yang mampu menjalar dengan kecepatan hingga $900 \mathrm{~km} / \mathrm{jam}$, terutama ditimbulkan oleh gempabumi yang terjadi di dasar laut. Kecepatan gelombang tsunami bergantung pada kedalaman laut. Di laut dengan kedalaman $7000 \mathrm{~m}$ misalnya, kecepatannya bisa mencapai $942,9 \mathrm{~km} / \mathrm{jam}$. Kecepatan ini hampir sama dengan kecepatan pesawat jet. Berbeda dengan gelombang laut biasa, tsunami memiliki panjang gelombang antara dua puncaknya lebih dari $100 \mathrm{~km}$ di laut lepas dan selisi waktu antara puncak-puncak gelombangnya berkisar antara 10 menit hingga 1 jam. Saat mencapai pantai yang dangkal, teluk, atau muara sungai gelombang ini menurun kecepatannya, namun tinggi gelombangnya meningkat puluhan meter dan bersifat merusak (Anonim, 2014).

Ketinggian tsunami di laut dalam hanya mencapai 30-60 cm, dengan panjang gelombang mencapai ratusan kilometer, sehingga keberadaan tsunami di laut dalam sulit dibedakan dengan gelombang biasa, bahkan tidak dirasakan oleh kapal-kapal yang sedang berlabuh di tengah samudera. Berbeda dengan gelombang karena angin, dengan hanya bagian permukaan atas yang bergerak, gelombang tsunami mengalami pergerakan diseluruh bagian badan air, mulai dari permukaan sampai bagian dalam samudera (Sugito, 2008).

Menurut Eze dkk. (2009) hubungan antara kecepatan rambat gelombang tsunami dan kedalaman laut dihitung berdasarkan persamaan:

$v=\sqrt{g h}$

dengan:

$v=$ Kecepatan rambat tsunami $(\mathrm{m} / \mathrm{s})$

$g=$ Percepatan gravitasi $\left(\mathrm{m} / \mathrm{s}^{2}\right)$

$h=$ Kedalaman laut $(\mathrm{m})$

Menurut Sutrisno (2007) episenter gempabumi adalah tempat asal mula terbentuknya tunami di laut. Kecepatan tsunami berbeda untuk setiap kedalaman laut yang berbeda, sehingga kecepatan tsunami yang menuju pantai berubah dari $v(x)_{0}$, $v(X)_{1}, v(x)_{2}, v(x)_{3}, \ldots, v(x)_{n}$. Waktu tiba $(t)$ gelombang tsunami di pantai dihitung dengan memperhatikan perubahan kedalaman laut yang dilewati gelombang tsunami. Lintasan tempuh gelombang tsunami dari sumber tsunami hingga ke pantai mengalami perubahan kedalaman yaitu akan semakin dangkal saat mendekati pantai. Kondisi ini diselesaikan dengan membagi panjang lintasan $x$ kedalam elemen panjang $d x_{i}$ dengan asumsi pada jarak $d x_{i}$ kedalaman laut tetap. Kecepatan gelombang pada kedalaman tersebut adalah $v_{i}(i=1,2,3, \ldots .$. , dst). Jika $d x_{i}=d x$, maka waktu tiba gelombang tsunami dapat dihitung seperti berikut:

$$
\begin{aligned}
\sum_{i=1}^{n} t=\int_{0}^{x_{1}} \frac{d x}{v(x)_{1}} & +\int_{x_{1}}^{x_{2}} \frac{d x}{v(x)_{2}}+\int_{x_{2}}^{x_{3}} \frac{d x}{v(x)_{3}}+\ldots \\
& +\int_{x_{n-1}}^{x_{n}} \frac{d x}{v(x)_{n}} \quad \ldots \ldots \ldots \ldots \ldots .2
\end{aligned}
$$

dengan:

$t \quad=$ Waktu tiba gelombang tsunami (s)

$v(x)=$ Kecepatan tsunami di setiap posisi $(\mathrm{m} / \mathrm{s})$

$d x=$ Jarak setiap titik lintasan $(\mathrm{m})$

(WinITDB, 2007)

Menurut Kaharuddin dkk. (2011) jenis gempabumi di dasar laut yang berpotensi menimbulkan tsunami memiliki sifat dan kondisi:

1. Kekuatan gempa diatas $6 \mathrm{SR}$.

2. Gempabumi dangkal yaitu gempabumi di kedalaman lebih kecil dari $60 \mathrm{~km}$ dari permukaan laut.

3. Kedalaman air yang cukup ( 500 - $5000 \mathrm{~m}$ ).

4. Letak fokus gempa berada pada bagian luar tebing laut yang curam terhadap daratan (luar zona subduksi).

5. Terjadi pola pergerakan sesar secara vertikal.

Lautrup (2005) menggunakan model yang dinamakan "waterberg" untuk memperkirakan energi yang terkandung dalam air yang terdorong oleh patahan naik (reverse fault). Model "waterberg" mengasumsikan seluruh kolom air diatas patahan 
terdorong bersama patahan naik sesaat setelah gempabumi, sehingga volume kolom air yang terdorong ke atas sama dengan volume patahan naik yaitu perkalian panjang patahan $(L)$, lebar patahan $(W)$ dan deformasi dasar laut $(D)$. Dari argumen tersebut, maka massa air $\left(M_{a}\right)$ yang mengalami gangguan kesetimbangan dan selanjutnya dirambatkan sebagai gelombang tsunami adalah:

$M_{a}=\rho L W D$

dengan:

$M_{a}=$ Massa air $(\mathrm{kg})$

$\rho=$ Massa jenis air $\left(\mathrm{kg} / \mathrm{m}^{3}\right)$

$L=$ Surface rupture length/panjang patahan $(\mathrm{m})$

$W=$ Rupture width/ lebar patahan $(\mathrm{m})$

$D=$ Maximum displacement/deformasi dasar laut $(\mathrm{m})$ (Lautrup, 2005)

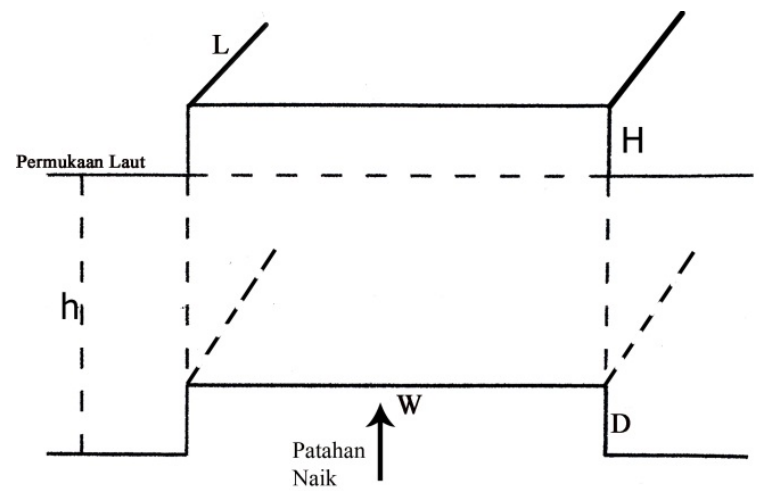

Gambar 1. Model "waterberg" tsunami yang terbangkitkan oleh patahan naik.

Volume massa air yang terangkat dari titik kesetimbangan adalah $V=L W D$. Massa air yang terangkat dari titik kesetimbangan adalah $M=\rho V=$ $\rho L W D$. Jika tinggi rata-rata setiap partikel air yang terdorong oleh gerakan patahan naik sebesar $\mathrm{D} / 2$, maka besar selisi energi potensial akibat terdorongnya massa air oleh patahan naik yaitu:

$E=M g \cdot \frac{1}{2} D=\frac{1}{2} \rho L W g D^{2}$

dengan:

$E=$ Energi potensial air (joule)

$\rho=$ Massa jenis air $\left(\mathrm{kg} / \mathrm{m}^{3}\right)$

$L=$ Surface rupture length/ panjang patahan $(\mathrm{m})$

$W=$ Rupture width/ lebar patahan (m)

g = Gravitasi $\left(\mathrm{m} / \mathrm{s}^{2}\right)$

$D=$ Deformasi dasar laut $(\mathrm{m})$

(Lautrup, 2005)

Rumus untuk menghitung ketinggian gelombang tsunami yaitu:

$H_{n}=\sqrt[4]{\frac{h_{n-1}}{h_{n}}} \sqrt{\frac{b_{n-1}}{b_{n}}} H_{n-1}$

dengan: $\mathrm{n}=$ Bernilai dari 1, 2, 3, 4, dst. $\mathrm{n}$ membesar ke arah pantai.

$H_{n} \quad=$ Tinggi gelombang pada kedalaman $n(m)$

$H_{n-1}=$ Tinggi gelombang pada kedalaman n-1 (m)

$h_{\mathrm{n}} \quad=$ Kedalaman perairan ke $\mathrm{n}(\mathrm{m} / \mathrm{s})$

$h_{\mathrm{n}-1}=$ Kedalaman perairan ke $\mathrm{n}-1$ (m/s)

$b_{n}=$ Jarak antar arah rambat gelombang pada kedalaman $\mathrm{n}(\mathrm{m})$

$b_{n-1}=$ Jarak antar arah rambat gelombang pada kedalaman $\mathrm{n}-1(\mathrm{~m})$

(Bryant, 2008)

\section{2. $\quad$ Metode}

Penelitian menggunakan data historis tsunami yang diperoleh dari Katalog NOAA (National Oceanic and Atmospheric Administration) tahun 1890 2014. Daerah yang di teliti adalah Wilayah Sulawesi Utara yang terletak pada $00^{\circ} 15^{\prime} 51^{\prime \prime} \mathrm{LU}$ -

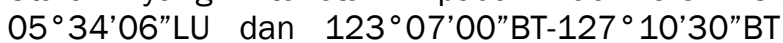
daerah pesisir utara, Sulawesi Utara. Sumber gempabumi penyebab tsunami terletak pada $4^{\circ} \mathrm{LU}$ - 8ㄴU dan 119० BT - 126 BT. Data diolah menggunakan Software WinITDB.

\section{Hasil dan Pembahasan}

\subsection{Kejadian Tsunami A}

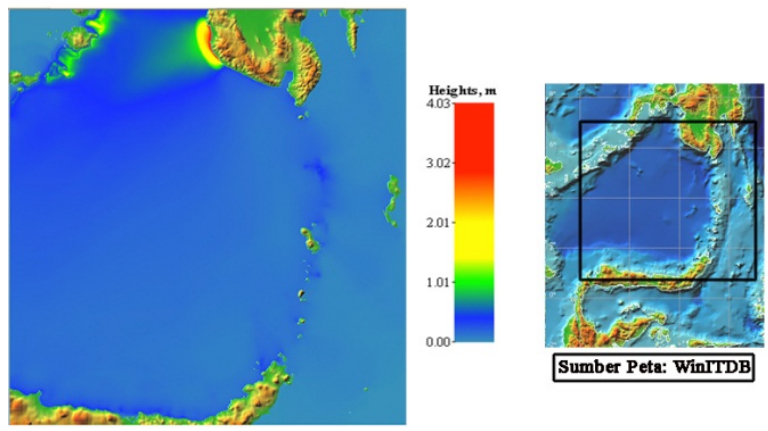

Gambar 2. Peta simulasi penjalaran tsunami dari pusat gempabumi 6,50 LU dan 124 BT dengan magnitudo 7,2 SR.

Kejadian Tsunami A merupakan tsunami yang diakibatkan oleh gempabumi dengan magnitudo 7,2 SR yang berada pada koordinat 6,50 LU dan 124,00 BT. Gempabumi bermagnitudo 7,2 SR, menyebaban panjang patahan $47,4241 \mathrm{~km}$, lebar patahan yaitu 29,1742 km, dan deformasi dasar laut yaitu 1,7701 $\mathrm{m}$. Tinggi maksimum gelombang tsunami yang terbentuk akibat gempabumi pada Kejadian A adalah 4,03 meter. Tsunami yang terbangkitkan akibat gempabumi A masuk dalam klasifikasi tsunami yang tidak berbahaya untuk wilayah pesisir utara Sulawesi Utara karena tinggi maksimum gelombang tsunami yang menerjang wilayah pesisir utara Sulawesi Utara lebih kecil dari 0,5 meter. 


\subsection{Kejadian Tsunami B}

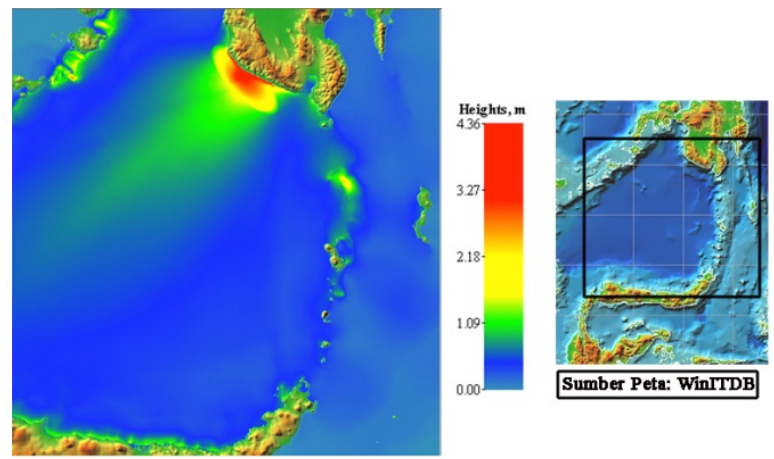

Gambar 3. Peta simulasi penjalaran tsunami dari pusat gempabumi 6,0328 LU dan 124,2489 BT dengan magnitudo 7,5 SR.

Kejadian tsunami B merupakan tsunami yang diakibatkan oleh gempabumi dengan magnitudo 7,5 SR pada koordinat 6,0328 LU dan 124,2489 BT. Gempabumi bermagnitudo 7,5 SR menyebabkan panjang patahan yaitu $73,2824 \mathrm{~km}$, lebar patahan yaitu 29,1742 km, dan deformasi dasar laut yaitu 2,1627 km. Tsunami yang terbangkitkan akibat gempabumi B masuk dalam klasifikasi cukup berbahaya untuk daerah Bintauna dengan tinggi gelombang maksimum 0,5 meter dan Kaidipang dengan tinggi gelombang maksimum 0,65 meter. Selain dari dua daerah tersebut tsunami yang terbangkitkan diklasifikasikan tidak berbahaya karena tinggi gelombang maksimum lebih kecil dari 0,5 meter.

\subsection{Kejadian Tsunami C}
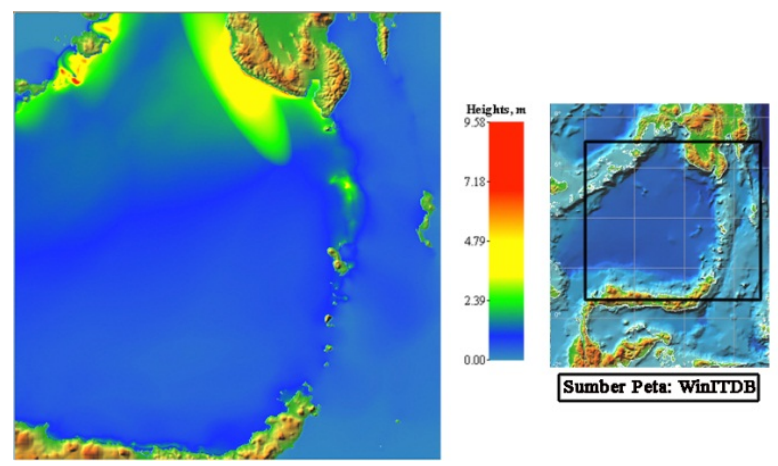

Gambar 4. Peta simulasi penjalaran tsunami dari pusat gempabumi 6,2617 LU dan 124,0228 BT dengan magnitudo 8,0 SR.

Kejadian tsunami C merupakan tsunami yang diakibatkan oleh gempabumi dengan magnitudo 8,0 SR pada koordinat 6,2617 LU dan 124,0228 BT. Gempabumi dengan magnitudo 8,0 SR maka panjang patahan yaitu 151,3561 km, lebar patahan yaitu 46,7735 km, dan deformasi dasar laut yaitu 3,0199 m. Tsunami yang terbangkitkan akibat gempabumi B masuk dalam klasifikasi cukup berbahaya untuk daerah Bintauna, Poigar, Amurang, Lolak, Tombariri, Kaidipang dan Siau Barat karena tinggi gelombang maksimum berapa pada 0.5 meter $\leq \mathrm{H}<1.5$ meter. Pada wilayah Beo, Manado, dan Tahuna tinggi maksimum gelombang tsunami masuk dalam klasifikasi tidak berbahaya karena tinggi gelombang lebih kecil dari 0,5 meter.

\subsection{Kejadian Tsunami D}

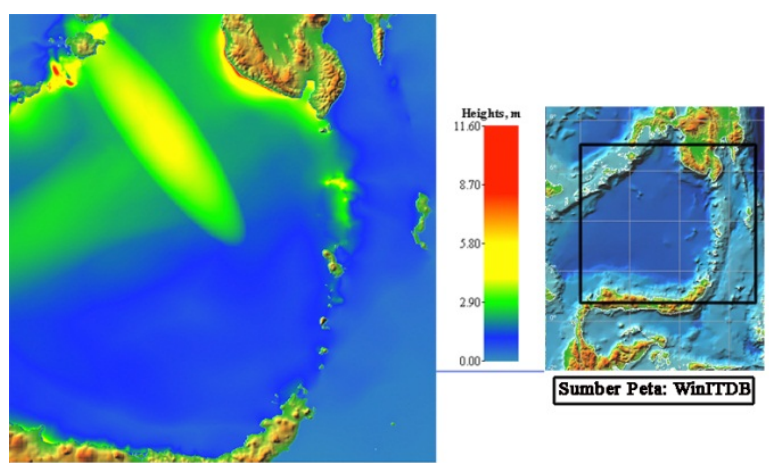

Gambar 5. Peta Simulasi Penjalaran Tsunami Dari Pusat Gempabumi 5,50 LU Dan 123 BT Dengan Magnitudo 8,3 SR

Kejadian tsunami D merupakan tsunami yang diakibatkan oleh gempabumi dengan magnitudo 8,3 SR pada koordinat 5,5 LU dan 123 BT. Apabila terjadi gempabumi dengan magnitudo 8,3 SR maka panjang patahan yaitu $233,8837 \mathrm{~km}$, lebar patahan yaitu $62,0869 \mathrm{~km}$, dan deformasi dasar laut yaitu 3,6897 m. Tsunami yang terbangkitkan akibat gempabumi B masuk dalam klasifikasi bahaya untuk wilayah Kaidipang karena tinggi gelombang maksimum berapa pada $1.5 \mathrm{~m} \leq \mathrm{H}<3 \mathrm{~m}$, cukup bahaya untuk wilayah Bintauna, Lolak, Poigar, Amurang, Tombariri, Manado, Siau Barat, Beo karena tinggi gelombang maksimum berada pada 0.5 meter $\leq \mathrm{H}<1.5$ meter. Pada wilayah tahuna tinggi maksimum gelombang tsunami masuk dalam klasifikasi tidak berbahaya karena tinggi gelombang lebih kecil dari 0,5 meter.

\subsection{Kejadian Tsunami E}

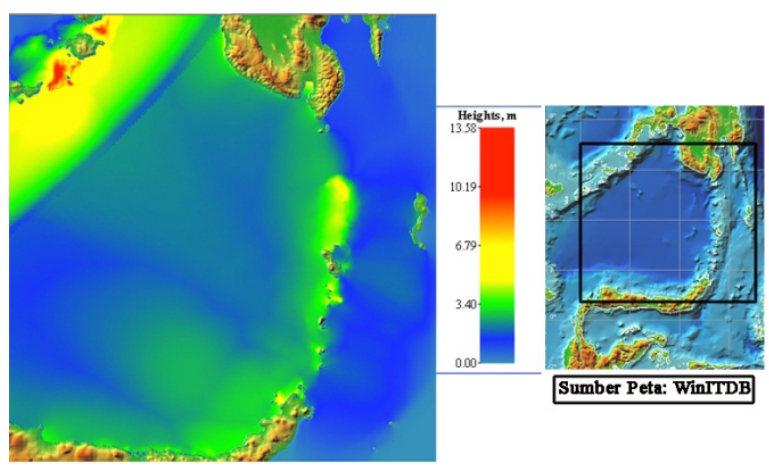

Gambar 6. Peta Simulasi Penjalaran Tsunami dari Pusat Gempabumi 6 LU dan 122 BT dengan Magnitudo 8,7 SR.

Kejadian tsunami E merupakan tsunami yang diakibatkan oleh gempabumi dengan magnitudo 8,7 SR pada koordinat 6 LU dan 122 BT. Apabila terjadi gempabumi dengan magnitudo 8,7 SR maka 
panjang patahan yaitu $417,8303 \mathrm{~km}$, lebar patahan yaitu 90,8194 km, dan deformasi dasar laut yaitu 4,8194 km. Tsunami yang terbangkitkan akibat gempabumi E masuk dalam klasifikasi sangat bahaya untuk seluruh wilayah pesisir utara daerah Sulawesi Utara karena tinggi gelombang maksimum $\mathrm{H} \geq 3 \mathrm{~m}$, kecuali Beo karena tinggi gelombang maksimum yaitu 2,3 meter berada pada klasifikasi 1.5 meter $\leq \mathrm{H}<3$ meter.

\section{Kesimpulan \\ Berdasarkan hasil penelitian, dapat} disimpulkan bahwa:

1. Waktu tiba minimum tsunami yang diakibatkan oleh gempabumi dengan episenter di selatan Filipina dari tahun 1800 sampai 2014 pada kedalaman $\leq 60 \mathrm{~km}$ dan magnitude $\geq 7,0 \mathrm{SR}$ terhadap pantai di wilayah Sulawesi Utara yaitu menerjang Siau Barat pada menit ke-18 dengan tinggi tsunami 0,6 meter dan waktu tiba maksimum yaitu menerjang Bintauna pada menit ke-35 dengan tinggi tsunami 1,1 meter.

2. Tinggi maksimum gelombang tsunami yang diakibatkan oleh gempabumi dengan episenter di selatan Filipina dari tahun 1800 sampai 2014 pada kedalaman $\leq 60 \mathrm{~km}$ dan magnitude $\geq 7,0$ SR terhadap pantai di wilayah Sulawesi Utara yaitu menerjang Kaidipang dengan tinggi 4,5 meter pada menit ke-43 dan tinggi minimum gelombang tsunami menerjang Beo dengan tinggi 2,3 meter pada menit ke 55.

3. Daerah yang termasuk dalam klasifikasi tsunami sangat bahaya $\mathrm{H} \geq 3$ meter yaitu Kaidipang, Bintauna, Lolak, Poigar, Amurang, Tombariri, Manado, Siau Barat dan Tahuna. Satu-satunya yang termasuk dalam klasifikasi tsunami bahaya $1.5 \mathrm{~m} \leq \mathrm{H}<3 \mathrm{~m}$ yaitu Beo.

\section{Daftar Pustaka}

Anonim. 2014. Gempabumi dan Tsunami. Direktorat Jenderal Geologi dan Sumber Mitigasi Bencana Geologi, Bandung.

Athanasius, C. 2009. Pengaruh Geomorfologi Pantai Terhadap Gelombang Tsunami. Bulletin Vulkanologi dan Bencana Geologi. 4: 39-51

Aydan, 0. 2008. Seismic and Tsunami Hazard Potential in Indonesia with a special emphasis on Sumatra Island. Journal of The School of Marine Science and Technology.6: 19-38

Bryant, E. 2008.Tsunami: Underrated Hazard. Springer and Praxis Publishing, London.

Eze, C. L., Uko, D. E., Sigalo, F. B., Israel-Cookey. C. (2009). Mathematical Modelling of Tsunami Propagation. Journal of Applied Sciences and Environmental Management. 13: 9-12

Sugito, N.T. 2008. Tsunami. Universitas Pendidikan Indonesia, Bandung.

Sutrisno. 2007. Penentuan Waktu Datang Gelombang Tsunami di Beberapa Kota Pantai Selatan Jawa Barat Sebagai Informasi Penting Dalam Usaha Penyelamatan Secara Preventif Menghadapi Bencana Tsunami. Universitas Islam Negeri Syarif Hidayatullah, Jakarta.

Lautrup. 2005. Tsunami Physics. The Niels Bohr Institute, Copenhagen.

Seminar on-Air Bioteknologi untuk Indonesia. HIm 25.

Yuningsih, R. Damayanti, dan L. Udarno. 2004.Efek Toksiko-Patologik beberapa Tanaman Beracun pada Mencit dalam Upaya Mencari Zat Pengganti Racun Strychnine untuk Pemberantasan Penyakit Rabies pada Anjing. Seminar Nasional Teknik Peternakan. 96: 767 - 775. 